\title{
Preparation of Antibacterial Nanofibre/Nanoparticle Covered Composite Yarns
}

\author{
Fatma Yalcinkaya, ${ }^{1}$ Michal Komarek, ${ }^{1}$ Daniela Lubasova, ${ }^{1}$ \\ Filip Sanetrnik, ${ }^{1,2}$ and Jiri Maryska ${ }^{1}$ \\ ${ }^{1}$ Department of Nanotechnology and Informatic, Institute for Nanomaterials, Advanced Technologies and Innovation, \\ Technical University of Liberec, 46117 Liberec, Czech Republic \\ ${ }^{2}$ Department of Nonwoven and Nanofibrous Materials, Faculty of Textile Engineering, Technical University of Liberec, \\ 46117 Liberec, Czech Republic
}

Correspondence should be addressed to Fatma Yalcinkaya; yenertex@hotmail.com

Received 16 November 2015; Revised 6 January 2016; Accepted 12 January 2016

Academic Editor: Tamer Uyar

Copyright (C) 2016 Fatma Yalcinkaya et al. This is an open access article distributed under the Creative Commons Attribution License, which permits unrestricted use, distribution, and reproduction in any medium, provided the original work is properly cited.

\begin{abstract}
The antibacterial efficiency of nanofibre composite yarns with an immobilized antibacterial agent was tested. This novel type of nanofibrous composite material combines the good mechanical properties of the core yarn with the high specific surface of the nanofibre shell to gain specific targeted qualities. The main advantages of nanofibre covered composite yarns over the standard planar nanofibre membranes include high tensile strength, a high production rate, and their ability to be processed by standard textile techniques. The presented paper describes a study of the immobilization of an antibacterial agent and its interaction with two types of bacterial colonies. The aim of the study is to assess the applicability of the new composite nanomaterial in antibacterial filtration. During the experimental tests copper(II) oxide particles were immobilized in the polyurethane and polyvinyl butyral nanofibre components of a composite yarn. The antibacterial efficiency was evaluated by using both Gram-negative Escherichia coli and Gram-positive Staphylococcus gallinarum bacteria. The results showed that the composite yarn with polyvinyl butyral nanofibres incorporating copper(II) oxide nanoparticles exhibited better antibacterial efficiency compared to the yarn containing the polyurethane nanofibres. The nanofibre/nanoparticle covered composite yarns displayed good antibacterial activity against a number of bacteria.
\end{abstract}

\section{Introduction}

Nanofibrous materials have attracted a huge amount of interest during the last few decades mainly in the framework of research and innovation studies. Their high surface area, high porosity, small pore size, and compatibility with functionalizing additives mean that they are promising for various applications including filtration, membranes, medical applications, sensors, catalysts, and enzyme carriers [1-10]. Many scientists focus on evaluating the activity and application of nanofibres and nanoparticles [3, 11-13]. However, most of their work is done on a laboratory scale and future developments in technology are anticipated.
In addition to the laboratory scale, there are several companies which produce nanofibres on an industrial scale using various production methods. The most commonly used methods include melt blowing, centrifugal spinning, islandin-the-sea splitting, and needleless electrospinning [14-16]. Each technology has its own advantages and disadvantages. For instance, melt blowing is an environmentally friendly technology with a high production rate; however, the fibre diameter is usually high and the diameter distribution is very wide. This method has an additional problem with die clogging. Island-in-the-sea bicomponent fibre splitting is another technology suitable for the production of nanofibres with relatively high productivity; however, the resultant fibres 
are tangled and it is difficult to separate them from each other. In the case of centrifugal spinning, production rate is high but with a wide fibre diameter distribution.

In this work, the needleless electrospinning process was used to eliminate the disadvantages of productivity and wide fibre diameter distribution. Specifically, the needleless roller electrospinning method developed by Jirsak et al. was used [17]. The disadvantage of the RES is the fact that not all polymer solutions can be spun into nanofibres. The reason for this has been explained in previous studies $[18,19]$. On the other hand, the RES system was found to be suitable for many polymer-solvent systems [18-21].

A modified RES system for the production of nanofibre/nanoparticle covered yarn was recently developed by Jirsak et al. [22]. In this system, instead of using a flat sheet collecting material, a textile yarn was used. The principle of the roller electrospinning system has been explained in more detail in previous works [20,21]. This method was used to cover the core yarn with nanofibres. Afterwards, a supporting yarn was covered around the composite yarn to improve the abrasion resistance of the nanofibre cover during further processing, for example, weaving.

Due to the intended use of the material in antimicrobial filters, the suitable antibacterial agent had to be immobilized in the nanofibre component of the composite yarn. There are many antibacterial agents available on the market but copper(II) oxide was chosen due to its long life and low cost. Two types of polymers, polyvinyl butyral (PVB) $[20,21]$ and polyurethane (PU) $[23,24]$, were tested in this study to form the nanofibre component of the system.

Compared to the antibacterial test where both $\mathrm{PU}$ and PVB were used, the PVB polymer solution was selected for the next step of the experiment. In the next step, the effects of the amounts of copper(II) oxide $(\mathrm{CuO})$ on the antibacterial efficiency were determined by changing its amount in the solution and changing the linear weight of nanofibres on the produced yarn.

For this paper it was important to produce the lowest possible efficient amount of nanofibres with an antibacterial agent at a high nanofibre composite yarn production speed, which is promising for industrial application.

\section{Materials and Methods}

PVB was purchased from Kuraray America Inc. (Mowital B $60 \mathrm{H}, 60,000 \mathrm{~g} / \mathrm{mol}$ ). PU Larithane LS 1086 (Novotex, Italy), which is an aliphatic elastomer composed of $2,000 \mathrm{~g} / \mathrm{mol}$ linear polycarbonate diol and isophorone diisocyanate and extended by isophorone diamine, was selected as the second polymer.

DMF (Fluka, Switzerland) was used as the solvent for the PU, whereas acetic acid (Penta, Czech Republic) was used as the solvent for the PVB. CuO nanoparticles were purchased from Penta (Czech Republic). The surfactant Triton X-100, obtained from Sigma Aldrich, was used to provide a uniform distribution of the $\mathrm{CuO}$ nanoparticles in the PVB and $\mathrm{PU}$ polymer solutions.

The principle of a modified RES system based on a rotating roller electrode was used. The electrode roller is

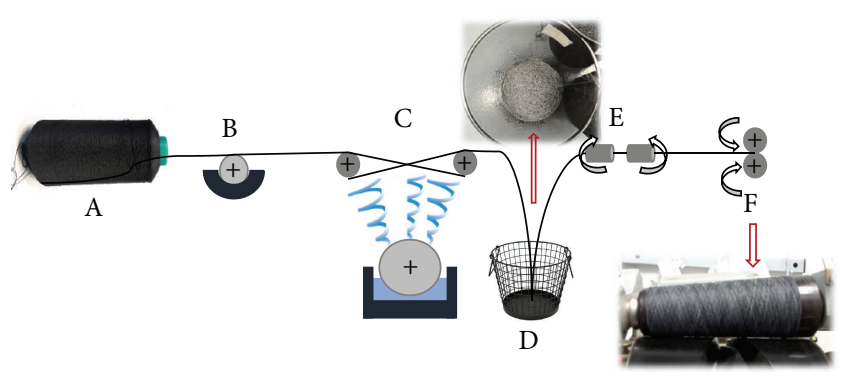

FIgURE 1: Schematic diagram of a continuous production device. A: black core yarn, B: application of a conductive solution, C: roller electrospinning system, D: collector, E: application of protective yarn(s), and F: take-up mechanism.

immersed in a polymer solution tank and connected to a high voltage source. As mentioned above, the modified RES system was used to cover the base yarn (Figure 1).

The morphology of the nanofibre covered yarns with $\mathrm{CuO}$ particles was evaluated using a Tescan Vega3 SB scanning electron microscope (SEM). The zero-shear viscosity of the polymer solutions was measured using a HAAKE Roto Visco rheometer at $25^{\circ} \mathrm{C}$. The antibacterial efficiency of the $\mathrm{CuO}$ agent immobilized in the composite yarns against Grampositive Staphylococcus gallinarum (S. gallinarum) and Gramnegative Escherichia coli (E. coli) was tested by the modified AATCC test method 100-2004.

\section{Experimental}

\subsection{Fabrication of Composite Nanofibrous Yarns}

3.1.1. Preparation of the Polymer Solutions. Two polymers, $\mathrm{PVB}$ and $\mathrm{PU}$, were tested for the production of nanofibre composite yarns in order to compare their antibacterial effect. PVB was selected because of its low cost, good mechanical properties, and nontoxicity of the solvent. PVB was dissolved in concentrated acetic acid to form an $11 \%$ wt. solution. A total of $10 \%$ wt. $\mathrm{CuO}$ was added to the PVB solution. PU was selected because of its high elasticity and the relatively good abrasion resistance of the nanofibre part of the composite. PU was dissolved in DMF to form a $15 \%$ wt. of solution and stirred overnight and then $10 \%$ wt. of $\mathrm{CuO}$ was added to the PU solution and dispersed using an ultrasonic disperser for 5 minutes. Finally, 1\% wt. of Triton X-100 surfactant was added to minimize the aggregation of the $\mathrm{CuO}$ nanoparticles. The bulk viscosity of the polymer solutions was measured to characterize the flow behaviour.

3.1.2. Electrostatic Spinning. A textured polyester base yarn (dtex $167 f 36 \times 1 \times 3$ ) was transported to the roller electrospinning system and used as a collector. After being covered by the nanofibres, the yarn was transported into the collector. Stable electrospinning conditions were used for both solution systems (Table 1).

To compare the antibacterial efficiency of the two solution systems, the speed of the yarn was set to $134 \mathrm{~m} / \mathrm{min}$. 
TABLE 1: Process parameters of the electrostatic spinning.

\begin{tabular}{lccccc}
\hline Applied voltage $(\mathrm{kV})$ & $\begin{array}{c}\text { Distance between } \\
\text { electrodes }(\mathrm{mm})\end{array}$ & $\begin{array}{c}\text { Speed of yarn on the } \\
\text { collector }(\mathrm{m} / \mathrm{min})\end{array}$ & Humidity $(\% \mathrm{RH})$ & Temperature $\left({ }^{\circ} \mathrm{C}\right)$ & Width of roller $(\mathrm{mm})$ \\
\hline 60 & 170 & $80-120-134-160-200$ & $18 \pm 1$ & $24 \pm 1$ & 470 \\
\hline
\end{tabular}

TABLE 2: Viscosity of PVB polymer solutions with 0,5 , and $10 \%$ wt. of $\mathrm{CuO}$ nanoparticles.

\begin{tabular}{lc}
\hline Sample and abbreviations & Viscosity (Pa.s) \\
\hline (P0) Content: $11 \%$ wt. PVB60H in $4 \%$ wt. $\mathrm{H}_{2} \mathrm{O}$ and & 0.30 \\
$85 \%$ wt. acetic acid mixture & \\
(P5) Content: $11 \%$ wt. PVB60H in $4 \%$ wt. $\mathrm{H}_{2} \mathrm{O}$, & \\
$1 \%$ wt. surfactant, $5 \%$ wt. $\mathrm{CuO}$, and $79 \%$ wt. acetic & 1.59 \\
acid mixture & \\
(P10) Content: $11 \%$ wt. PVB60H in $4 \%$ wt. $\mathrm{H}_{2} \mathrm{O}$, \\
$1 \%$ wt. surfactant, $10 \%$ wt. $\mathrm{CuO}$, and $74 \%$ wt. acetic \\
acid mixture
\end{tabular}

To optimize the concentration of $\mathrm{CuO}, 11 \%$ wt. of the PVB polymer solution with 0,5 , and $10 \%$ wt. of $\mathrm{CuO}$ was used during fabrication of the nanofibres covered yarns, and $1 \% \mathrm{wt}$. of surfactant was used to prevent aggregation. The viscosity of the solutions was measured and is included in Table 2.

The descriptions of the samples are listed in Table 3. The symbol "P" is the abbreviation for PVB, the number next to $\mathrm{P}$ is the amount of $\mathrm{CuO}$ particles (\% wt.) in the polymer solution, and the last number indicates the speed of composite yarn production.

3.1.3. Characterization of Amounts of Nanofibres in the Product. The amounts of $\mathrm{PVB} / \mathrm{CuO}$ nanofibres for different production speeds were evaluated by dissolving the specific nanofibre material in ethanol. Ethanol is a good solvent for PVB [25]. The $1 \mathrm{~m}$ samples were cut, weighed, and immersed in ethanol overnight. After dissolution of the nanofibrous component, the samples were washed with distilled water, dried, and weighed again. The results were calculated according to the following equation:

$$
\text { Amount of nanofibres }(\%)=\frac{\left(W_{0}-W_{1}\right)}{W_{0}} * 100
$$

where $W_{0}$ is the weight of composite yarn before nanofibre dissolution and $W_{1}$ is the weight of the yarn without nanofibres.

3.2. Antibacterial Test. Escherichia coli (E. coli) and Staphylococcus gallinarum (S. gallinarum) bacteria were purchased from the Czech Collection of Microorganisms, Masaryk University. Incubation of the bacteria was performed on a sterile agar with a broth agar medium from Oxoid Ceska Republika.

The antibacterial activities of the fabric systems were evaluated quantitatively in accordance with ASTM E 214901 and AATCC test method 100 (standard test method for determining the antibacterial activity of immobilized antibacterial agents under dynamic contact conditions).
The samples were sterilized in an oven at $80^{\circ} \mathrm{C}$ for $60 \mathrm{~min}$ before conducting the test. A blank sample was prepared without any antibacterial agent $(\mathrm{CuO})$. The antibacterial test against Gram-negative (E. coli) and Gram-positive ( $S$. gallinarum) was performed as the first step. The microorganisms were cultivated in a sterilized LB broth medium and then incubated overnight at $37^{\circ} \mathrm{C}$ in a shaking incubator. The bacterial suspensions employed for this test contained between $10^{2}$ and $10^{3}$ colony forming units (CFU).

Sterilized samples of nanofibre covered yarns were individually placed into a sterilized test tube and inoculated with $30 \mathrm{~mL}$ of $E$. coli or S. gallinarum bacterial suspension. At " 0 " contact time and after 1, 2, 3, 4, and 24 hours, $600 \mu \mathrm{L}$ of bacterial suspension was extracted and quickly spread on tryptic soy agar plates. The number of viable E. coli or $S$. gallinarum was determined by plating the extracted solution onto the Tryptic Soy agar plates and counting the colonies after 24 hours of incubation at $37^{\circ} \mathrm{C}$.

Three selected yarns P0-200, P5-200, and P10-200 (each around $1 \pm 0.01 \mathrm{~g}$ ) were used for the disinfection test. The disinfection test was performed on the selected samples against Gram-negative (E. coli) and Gram-positive (S. gallinarum) bacteria. The bacterial suspensions contained $10^{6}$ colony forming units (CFU).

The percentage reduction of test microorganisms in the test tubes with the nanofibre membranes was calculated using the following equation:

$$
\text { Reduction } \%=\frac{\left(A_{0}-A_{1}\right)}{A_{0}} * 100 \text {, }
$$

where $R$ is the percentage reduction of test microorganism; $A_{1}$ is the number of bacteria recovered from the inoculated nanofibre membrane with the nanoparticles in the test tube after specified contact time, and $A_{0}$ is the number of bacteria recovered from the inoculated nanofibre membrane with the nanoparticles in the test tube at " 0 " contact time.

\section{Results and Discussion}

4.1. Morphology Characterization. A polyester base yarn was covered with nanofibres/NPs and then a polyamide filament was used to protect against mechanical abrasion. The SEM images of the nanofibre/NP covered yarns made of $15 \%$ wt. PU with $10 \%$ wt. $\mathrm{CuO}$ and $11 \%$ wt. PVB with $10 \%$ wt. $\mathrm{CuO}$ are shown in Figure 2.

Figure 2 shows the nanofibres/NPs on the surface of the core yarn. Beads are present on the surface of the nanofibres. The number of beads on the $\mathrm{PVB} / \mathrm{CuO}$ yarns is higher than the number on the $\mathrm{PU} / \mathrm{CuO}$ yarns. These beads can be caused by aggregation of $10 \% \mathrm{wt}$. $\mathrm{CuO}$ or the low concentration of the PVB polymer solution compared to the PU solution. 
TABLE 3: Abbreviations of the second group of samples.

\begin{tabular}{|c|c|c|}
\hline Abbreviation & Content solution (\% wt.) & Speed of yarn $(\mathrm{m} / \mathrm{min})$ \\
\hline $\mathrm{P} 0-80$ & $11 \%$ wt. PVB60H in $4 \%$ wt. $\mathrm{H}_{2} \mathrm{O}$ and $85 \%$ wt. acetic acid mixture & 80 \\
\hline P0-120 & $11 \%$ wt. $\mathrm{PVB} 60 \mathrm{H}$ in $4 \%$ wt. $\mathrm{H}_{2} \mathrm{O}$ and $85 \%$ wt. acetic acid mixture & 120 \\
\hline P0-160 & $11 \%$ wt. $\mathrm{PVB} 60 \mathrm{H}$ in $4 \%$ wt. $\mathrm{H}_{2} \mathrm{O}$ and $85 \%$ wt. acetic acid mixture & 160 \\
\hline P0-200 & $11 \%$ wt. PVB60H in $4 \%$ wt. $\mathrm{H}_{2} \mathrm{O}$ and $85 \%$ wt. acetic acid mixture & 200 \\
\hline P5-80 & $11 \%$ wt. $\mathrm{PVB} 60 \mathrm{H}$ in $4 \%$ wt. $\mathrm{H}_{2} \mathrm{O}, 1 \%$ wt. surfactant, $5 \%$ wt. $\mathrm{CuO}$, and $79 \%$ wt. acetic acid mixture & 80 \\
\hline P5-120 & $11 \%$ wt. PVB60H in $4 \%$ wt. $\mathrm{H}_{2} \mathrm{O}, 1 \%$ wt. surfactant, $5 \%$ wt. $\mathrm{CuO}$, and $79 \%$ wt. acetic acid mixture & 120 \\
\hline P5-160 & $11 \%$ wt. PVB60H in $4 \%$ wt. $\mathrm{H}_{2} \mathrm{O}, 1 \%$ wt. surfactant, $5 \%$ wt. $\mathrm{CuO}$, and $79 \%$ wt. acetic acid mixture & 160 \\
\hline P5-200 & $11 \%$ wt. PVB60H in $4 \%$ wt. $\mathrm{H}_{2} \mathrm{O}, 1 \%$ wt. surfactant, $5 \%$ wt. $\mathrm{CuO}$, and $79 \%$ wt. acetic acid mixture & 200 \\
\hline P10-80 & $11 \%$ wt. PVB60H in $4 \%$ wt. $\mathrm{H}_{2} \mathrm{O}, 1 \%$ wt. surfactant, $10 \%$ wt. $\mathrm{CuO}$, and $74 \%$ wt. acetic acid mixture & 80 \\
\hline P10-120 & $11 \%$ wt. PVB60H in $4 \%$ wt. $\mathrm{H}_{2} \mathrm{O}, 1 \%$ wt. surfactant, $10 \%$ wt. $\mathrm{CuO}$, and $74 \%$ wt. acetic acid mixture & 120 \\
\hline P10-160 & $11 \%$ wt. PVB60H in $4 \%$ wt. $\mathrm{H}_{2} \mathrm{O}, 1 \%$ wt. surfactant, $10 \%$ wt. $\mathrm{CuO}$, and $74 \%$ wt. acetic acid mixture & 160 \\
\hline P10-200 & $11 \%$ wt. PVB60H in $4 \%$ wt. $\mathrm{H}_{2} \mathrm{O}, 1 \%$ wt. surfactant, $10 \%$ wt. $\mathrm{CuO}$, and $74 \%$ wt. acetic acid mixture & 200 \\
\hline
\end{tabular}

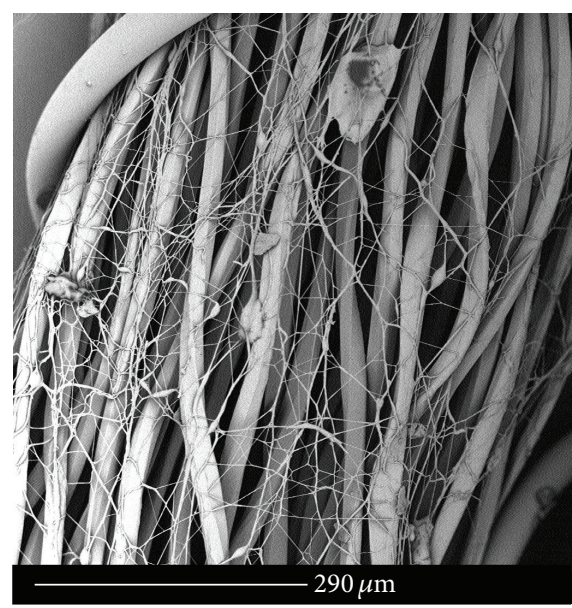

(a)

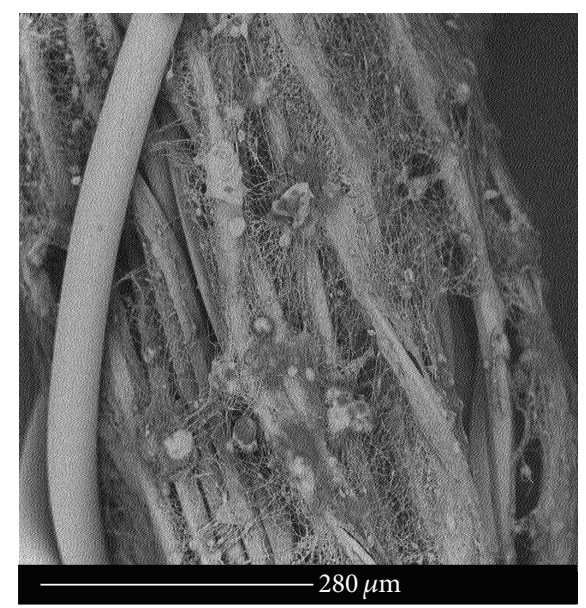

(b)

FIgure 2: SEM images of (a) PU/CuO, (b) PVB/CuO.

\subsection{Antibacterial Efficiency}

4.2.1. Dependence of the Antibacterial Efficiency on the Type of Nanofibre Polymer. The inhibition efficiency (\% reduction of bacteria colony) was calculated according to (2) and the results are shown in Figure 3. The results show that, even after 1 minute of contact of the bacteria with the $\mathrm{PVB} / \mathrm{CuO}$, the antibacterial efficiency is over $90 \%$. For each polymer, a blank sample without $\mathrm{CuO}$ was tested and a comparison showed that the bacterial colonies started to die after two hours.

This experiment shows that the antibacterial efficiency of nanofibre/NP covered yarns made from $\mathrm{PVB} / \mathrm{CuO}$ is much higher than nanofibre/NPs covered yarns made from $\mathrm{PU} / \mathrm{CuO}$. This could be explained by the formation of cupric acetate, which distributes the $\mathrm{Cu}^{2+}$ ions more homogenously than in the case of the nanoparticles. Acetic acid reacts with copper oxide to form cupric acetate. The reaction between $\mathrm{CuO}$ and acetic acid is shown in the following equation:

$$
2 \mathrm{CH}_{3} \mathrm{COOH}+\mathrm{CuO} \longrightarrow\left(\mathrm{CH}_{3} \mathrm{COO}\right)_{2} \mathrm{Cu}+\mathrm{H}_{2} \mathrm{O}
$$

4.2.2. Dependence of the Antibacterial Efficiency on the Amount of Nanofibres in the Product. Three polymer solutions, listed in Table 3 as P0-200, P5-200, and P10-200, were prepared with a constant PVB polymer concentration. From the previous experiment it was determined that the PVB dissolved in acetic acid with the $\mathrm{CuO}$ particles evinced an enormous antibacterial efficiency. It was determined that more than $90 \%$ of the bacteria died at " 0 " contact time of the nanofibre/NP covered yarns with the tested microorganism. This excellent antibacterial effect was observed after 1 hour. For that reason, the concentration of $\mathrm{CuO}$ was optimized (decreased) and various yarn speeds were used to improve productivity. To prevent aggregation of $\mathrm{CuO}$ particles, $1 \%$ wt. of nonionic Triton X-100 surfactant was used. PVB with $10 \%$ wt. of $\mathrm{CuO}$ has a very high bulk viscosity compared to the other samples. The viscosity results are shown in Table 2. High viscosity restricts the ability of the polymer solution to be electrospun into submicron fibres. As a result, a lower amount of nanofibres is collected on the yarn. SEM images show that the amount of nanofibres is lower but the amount 


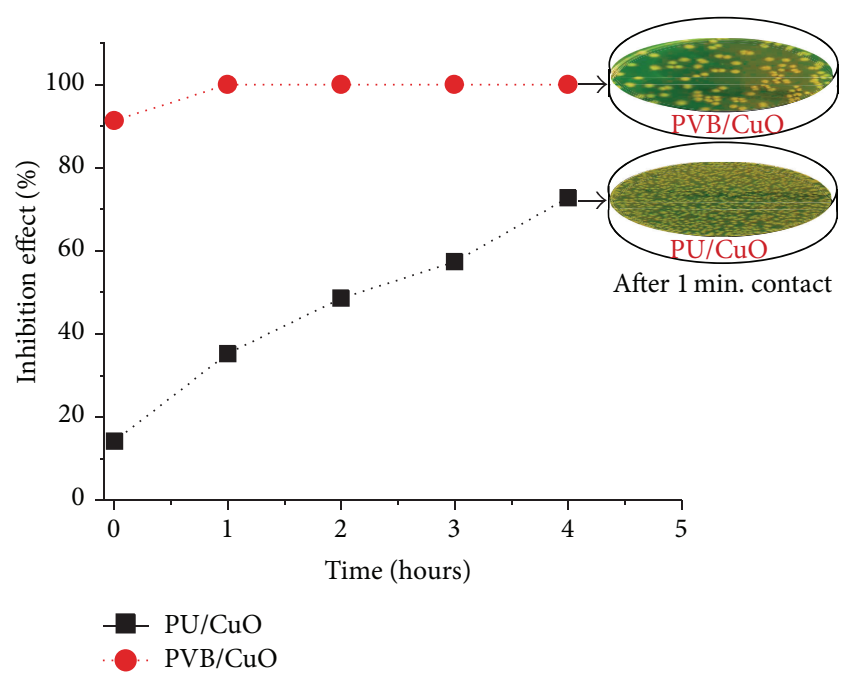

Figure 3: Reduction of bacteria (E. coli) overtime.

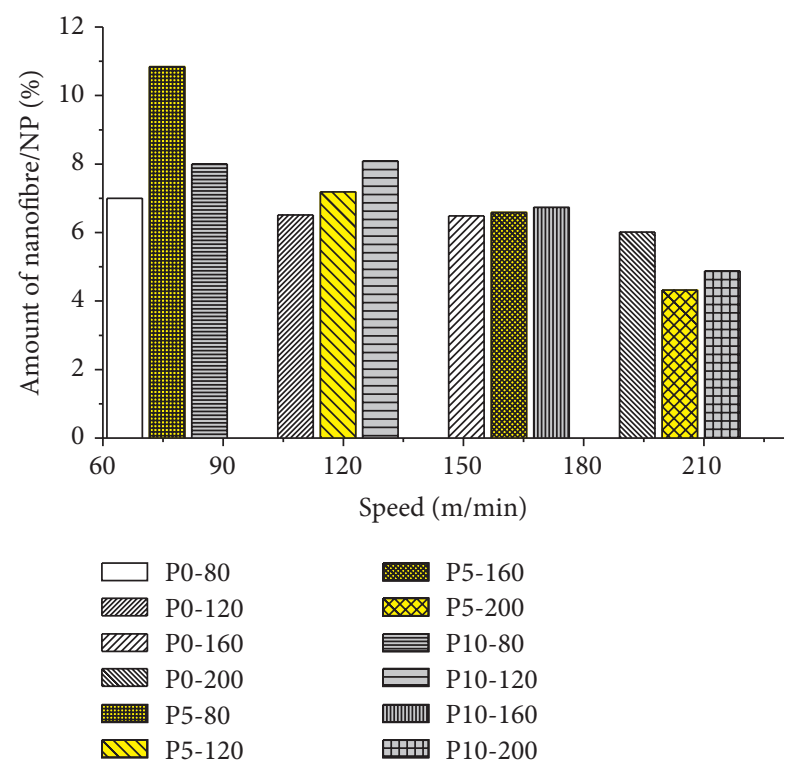

FIgURE 4: Amount of PVB/CuO nanofibres versus production speed of yarn. The amount of nanofibres on the yarn slightly decreased with an increase in speed due to a lower nanofibre collecting time.

of immobilized particles is higher in the case of $10 \%$ wt. of $\mathrm{CuO}$.

The percentage amounts of nanofibre covered base yarn were calculated according to (1) and are shown in Figure 4.

Figure 4 indicates that the change in the amount of nanofibre/NPs depends on the speed of production. P0 indicates that no $\mathrm{CuO}$ is immobilized in the nanofibre component, while P5 has 5\% wt. and P10 has $10 \%$ wt. of nanoparticles, respectively. When the speed of yarn production increases, the amount of nanofibres/NPs decreases on the surface of the composite yarn.

The aim of the experiment was to determine the lowest possible efficient amount of nanofibres and antibacterial agent. The results of the antibacterial efficiencies are shown in Figure 5. It was determined that PVB with $\mathrm{CuO}$ exhibits good antibacterial efficiency against E. coli and S. gallinarum. The amount of $5 \%$ wt. of $\mathrm{CuO}$ immobilized in PVB nanofibres showed an antibacterial efficiency of $99.99 \%$ at a production rate of $200 \mathrm{~m} / \mathrm{min}$. At " 0 " contact time more than $50 \%$ of $E$. coli and S. gallinarum bacteria were dead. $\mathrm{CuO}$ has a better antibacterial efficiency against $E$. coli at "0" contact time. On the other hand, after one hour contact time, no bacteria remained alive.

It can be seen that, even at high speeds and low amounts of nanofibres/NPs, $\mathrm{CuO}$ showed remarkable antibacterial properties against E. coli and S. gallinarum. It is possible to conclude that the production rate of the equipment can be increased with the same amount of $\mathrm{CuO}$ or the concentration of $\mathrm{CuO}$ can be decreased at a low yarn production speed. Both methods will show good results. For mass production, a higher yarn speed is more desirable.

Because the inhibition effect was found to be excellent even for nanofibre covered yarn with a lower concentration of $\mathrm{CuO}$, a higher $\left(10^{6} \mathrm{CFU} / \mathrm{mL}\right)$ bacteria inoculum was prepared as explained in Section 2. Three yarns, P0-200, P5-200, and P10-200, were selected for subsequent testing. These samples were produced at the highest production rate, which means that the amount of nanofibres or nanofibre/NPs is the lowest compared to the others. The antibacterial test was performed against Gram-positive and Gram-negative microorganisms and the results are shown in Figure 6.

The results of the experiment show that more than 50\% of $S$. gallinarum bacteria are killed by the immobilized agent at " 0 " contact time. In one hour, PVB with immobilized $\mathrm{CuO}$ has a disinfection effect in accordance with the high concentration of the tested bacteria inoculum $\left(10^{6} \mathrm{CFU}\right)$.

The results in Figure 6 show that the initial antibacterial efficiency of $\mathrm{CuO}$ against $S$. gallinarum is higher than that against $E$. coli at "0" contact time. $\mathrm{CuO}$ nanoparticles are more effective against Gram-positive microorganisms. After 1 hour contact time, it was observed that both Gram-positive and Gram-negative bacteria were successfully disinfected. It can be concluded that the $\mathrm{CuO}$ agent in PVB nanofibre composite yarn exhibits a $99.99 \%$ disinfection efficiency against $E$. coli and S. gallinarum bacteria even at high CFU.

\section{Conclusion}

In this work, composite yarns with a nanofibre cover were prepared by a modified needleless electrospinning method. The testing comprised two types of polymers (PU and PVB). The process properties affecting the quality of the nanofibre compound, for example, the solution concentration, viscosity, spinning distance, voltage, and air humidity, were empirically optimized. The effect of the production rate on the linear weight of the nanofibre cover was evaluated. An inversely proportional effect of the production speed on the linear weight of the nanofibre cover was confirmed.

In accordance with the intended use of the composite yarn in antimicrobial filtration cartilages, the antibacterial agent $\mathrm{CuO}$ was incorporated into the nanofibrous layers and the antibacterial performance of the materials was studied. 

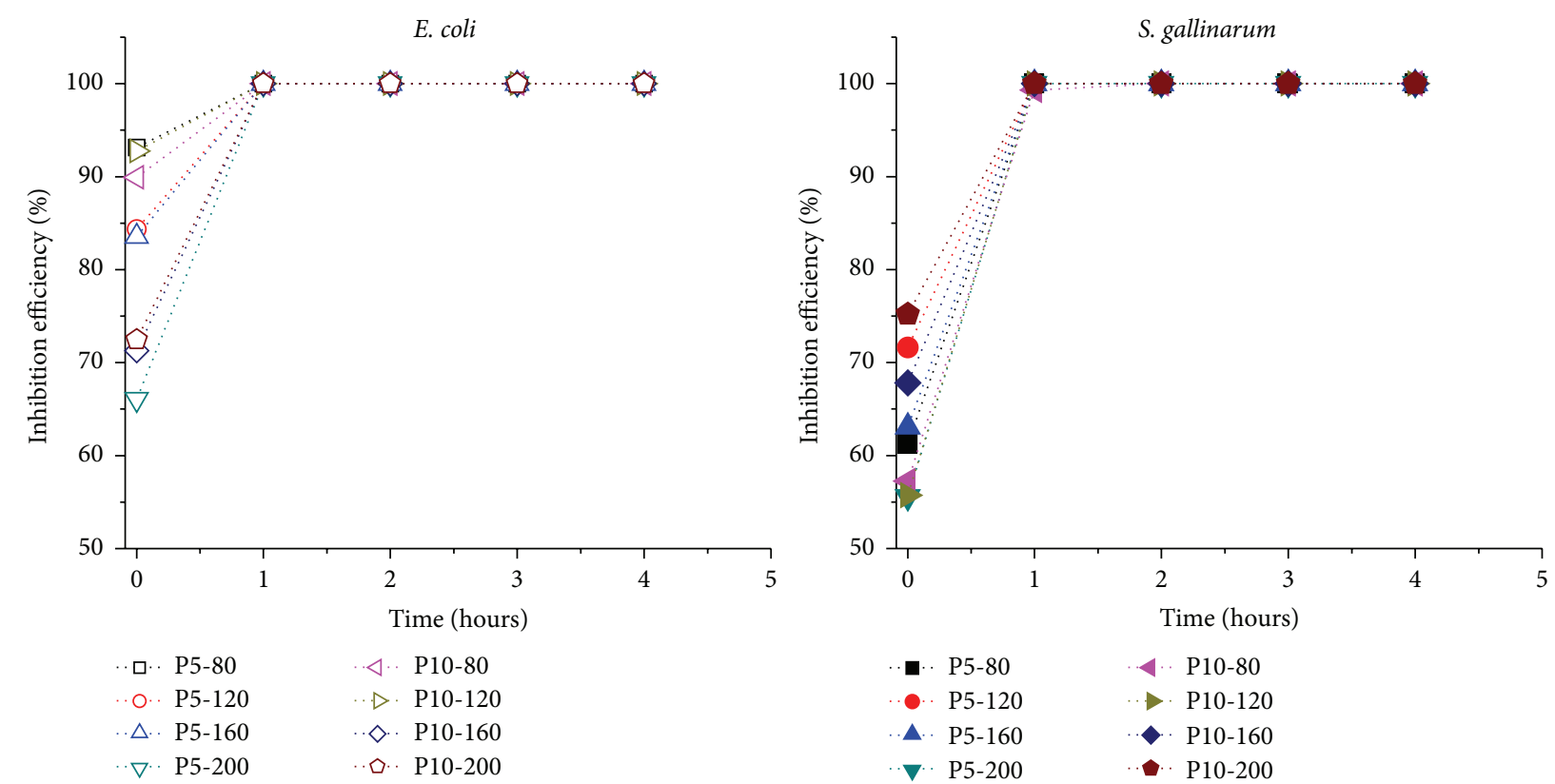

FIGURE 5: Antibacterial efficiency of nanofibre covered yarn with different concentrations of $\mathrm{CuO}$ agent.

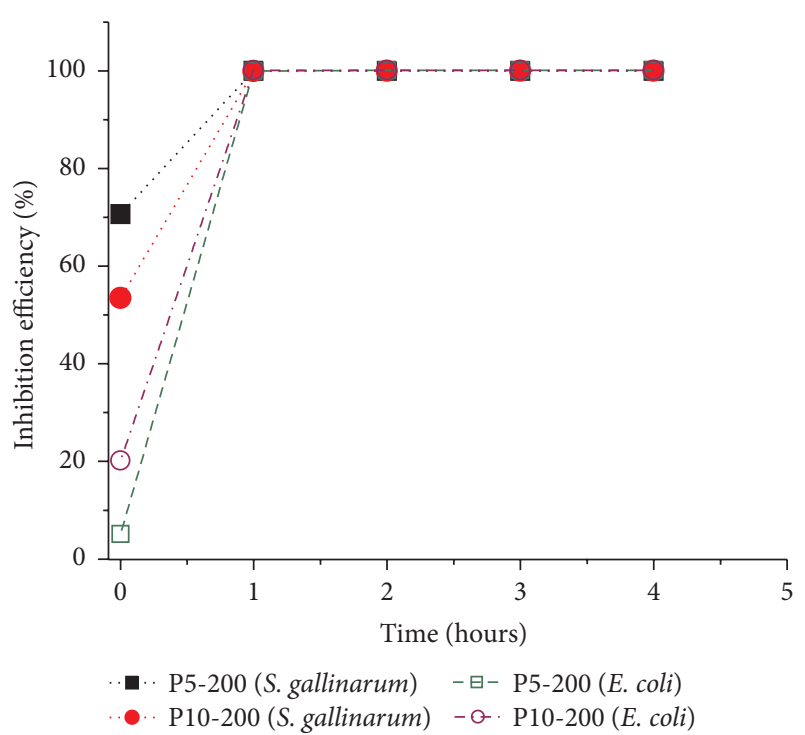

FIGURE 6: Antibacterial efficiency against $10^{6} \mathrm{CFU}$ bacterial concentrations.

The effect of the $\mathrm{CuO}$ concentration in the solution and the linear weight of the nanofibre cover on the antibacterial performance were measured.

Testing procedures comprised studies of the interaction of the prepared material with two bacterial types, that is, $E$. coli and S. gallinarum (Gram-positive and Gram-negative).

It was concluded through an evaluation of the sets of results that materials prepared by covering the core yarn with $\mathrm{PVB} /$ nanofibres with a $\mathrm{CuO}$ antibacterial agent generally show significantly higher antibacterial efficiency compared to yarns covered with PU nanofibres. This can be attributed to the better uniformity of the antibacterial agent distribution caused by the reaction of $\mathrm{CuO}$ with acetic acid creating copper acetate. Copper acetate then dissociates in the abundant acetic acid which helps to distribute the $\mathrm{Cu}^{2+}$ ions in the nanofibre mass. Better distribution of the $\mathrm{Cu}^{2+}$ ions enhances the probability of the contact between the antibacterial agent and the bacteria improving the overall antibacterial efficiency. The results showed that an antibacterial efficiency of $99.99 \%$ is achieved at $5 \%$ wt. of $\mathrm{CuO}$ additive and a production rate of $200 \mathrm{~m} / \mathrm{min}$. One hour contact is sufficient to disinfection all of the bacterial colonies.

The experimental work showed that the new type of composite nanofibrous yarns with immobilized antibacterial agents can be utilized to design antibacterial filtration cartridges for air and water purification.

\section{Conflict of Interests}

The authors declare that there is no conflict of interests regarding the publication of this paper.

\section{Acknowledgment}

The results of this project LO1201 were obtained through the financial support of the Ministry of Education, Youth and Sports in the framework of the targeted support of the "National Programme for Sustainability I."

\section{References}

[1] J. J. Ahire and L. M. T. Dicks, "2,3-Dihydroxybenzoic acidcontaining nanofiber wound dressings inhibit biofilm formation by Pseudomonas aeruginosa," Antimicrobial Agents and Chemotherapy, vol. 58, no. 4, pp. 2098-2104, 2014. 
[2] A. Fathi-Azarbayjani, L. Qun, Y. W. Chan, and S. Y. Chan, "Novel vitamin and gold-loaded nanofiber facial mask for topical delivery," AAPS PharmSciTech, vol. 11, no. 3, pp. 1164$1170,2010$.

[3] B.-H. Jang, O. Landau, S.-J. Choi, J. Shin, A. Rothschild, and I.D. Kim, "Selectivity enhancement of $\mathrm{SnO}_{2}$ nanofiber gas sensors by functionalization with Pt nanocatalysts and manipulation of the operation temperature," Sensors and Actuators B: Chemical, vol. 188, pp. 156-168, 2013.

[4] S. Lee and S. K. Obendorf, "Use of electrospun nanofiber web for protective textile materials as barriers to liquid penetration," Textile Research Journal, vol. 77, no. 9, pp. 696-702, 2007.

[5] W. Sambaer, M. Zatloukal, and D. Kimmer, "3D modeling of filtration process via polyurethane nanofiber based nonwoven filters prepared by electrospinning process," Chemical Engineering Science, vol. 66, no. 4, pp. 613-623, 2011.

[6] R. Vasita and D. S. Katti, "Nanofibers and their applications in tissue engineering," International Journal of Nanomedicine, vol. 1, no. 1, pp. 15-30, 2006.

[7] A. Zajicova, E. Javorkova, P. Trosan, M. Krulova, and V. Holan, "Drug-loaded nanofiber scaffolds for a simultaneous delivery of stem cells and immunosuppressive drugs in cell-based therapy and regenerative medicine," Journal of Tissue Engineering and Regenerative Medicine, vol. 8, pp. 277-278, 2014.

[8] D. Lubasova, A. Netravali, J. Parker, and B. Ingel, "Bacterial filtration efficiency of green soy protein based nanofiber air filter," Journal of Nanoscience and Nanotechnology, vol. 14, no. 7, pp. 4891-4898, 2014.

[9] L. Malinová, M. Stolínová, D. Lubasová, L. Martinová, and J. Brožek, "Electrospinning of polyesteramides based on epsiloncaprolactam and epsilon-caprolactone from solution," European Polymer Journal, vol. 49, no. 10, pp. 3135-3143, 2013.

[10] H. Kolya, S. Pal, A. Pandey, and T. Tripathy, "Preparation of gold nanoparticles by a novel biodegradable graft copolymer sodium alginate-g-poly (N,N-dimethylacrylamide-co-acrylic acid) with anti micro bacterial application," European Polymer Journal, vol. 66, pp. 139-148, 2015.

[11] C. D. Saquing, J. L. Manasco, and S. A. Khan, "Electrospun nanoparticle-nanofiber composites via a one-step synthesis," Small, vol. 5, no. 8, pp. 944-951, 2009.

[12] R. J. Tseng, J. Huang, J. Ouyang, R. B. Kaner, and Y. Yang, "Polyaniline nanofiber/gold nanoparticle nonvolatile memory," Nano Letters, vol. 5, no. 6, pp. 1077-1080, 2005.

[13] H. Wang, T. Wang, Y.-X. Ye et al., "Construction of an electrochemical cytosensor based on polyaniline nanofiber/gold nanoparticle interface and application to detection of cancer cells," Chinese Journal of Analytical Chemistry, vol. 40, no. 2, pp. 184-190, 2012.

[14] J. Harding, J. Keller, and R. Buntin, "Melt-blowing die for producing nonwoven mats," USA, Patent US 3825380 A, 1974.

[15] K. Sarkar, C. Gomez, S. Zambrano et al., "Electrospinning to Forcespinning," Materials Today, vol. 13, no. 11, pp. 12-14, 2010.

[16] R. Liu, N. Cai, W. Yang, W. Chen, and H. Liu, "Sea-island polyurethane/polycarbonate composite nanofiber fabricated through electrospinning," Journal of Applied Polymer Science, vol. 116, no. 3, pp. 1313-1321, 2010.

[17] O. Jirsak, F. Sanetrnik, D. Lukas, V. Kotek, L. Martinova, and J. Chaloupek, "A method of nanofibres production from a polymer solution using electrostatic spinning and a device for carrying out the method, Czech Republic," Article ID S7585437, US7585437 B2, 2005.
[18] F. Yener, B. Yalcinkaya, and O. Jirsak, "On the measured current in needle- and needleless electrospinning," Journal of Nanoscience and Nanotechnology, vol. 13, no. 7, pp. 4672-4679, 2013.

[19] B. Yalcinkaya, F. Yener, O. Jirsak, and F. Cengiz-Callioglu, "On the nature of electric current in the electrospinning process," Journal of Nanomaterials, vol. 2013, Article ID 538179, 10 pages, 2013.

[20] F. Yener and O. Jirsak, "Comparison between the needle and roller electrospinning of polyvinylbutyral," Journal of Nanomaterials, vol. 2012, Article ID 839317, 6 pages, 2012.

[21] F. Yener and O. Jirsak, "Improving performance of polyvinyl butyral electrospinning," in Proceedings of the 4th International Nanocon Conference, pp. 356-361, Brno, Czech Republic, 2011.

[22] O. Jirsak, F. Sanetrink, and J. Chaloupek, "Nanofiber-covered yarns," Chemical Fibers International, vol. 62, pp. 84-85, 2011.

[23] F. Yalcinkaya, B. Yalcinkaya, and O. Jirsak, "Influence of salts on electrospinning of aqueous and nonaqueous polymer solutions," Journal of Nanomaterials, vol. 2015, Article ID 134251, 12 pages, 2015.

[24] B. K. Kim, J. W. Seo, and H. M. Jeong, "Morphology and properties of waterborne polyurethane/clay nanocomposites," European Polymer Journal, vol. 39, no. 1, pp. 85-91, 2003.

[25] F. Yener, O. Jirsak, and R. Gemci, "Using a range of PVB spinning solution to acquire diverse morphology for electrospun nanofibres," Iranian Journal of Chemistry and Chemical Engineering, vol. 31, no. 4, pp. 49-58, 2012. 

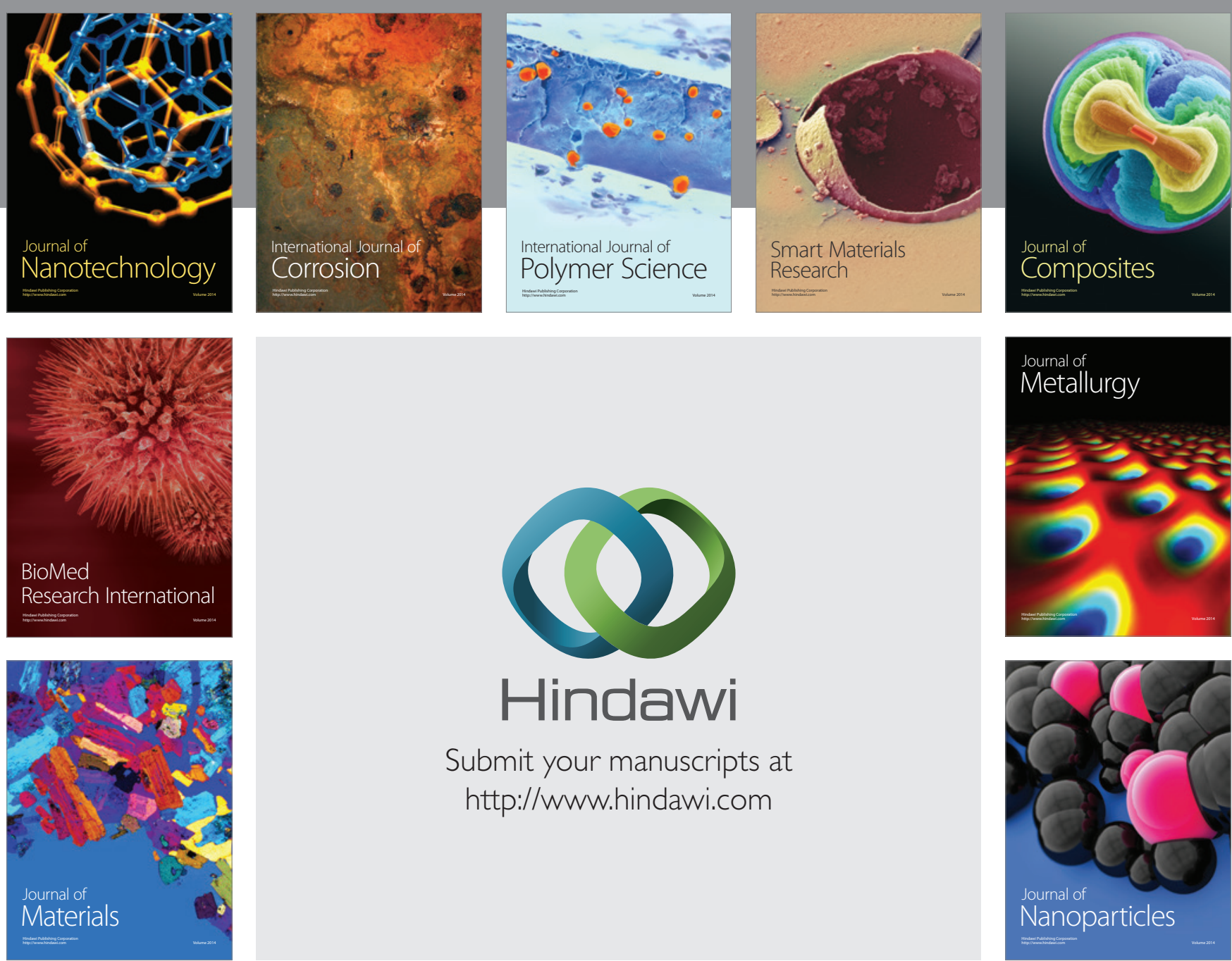

\section{Hindawi}

Submit your manuscripts at

http://www.hindawi.com

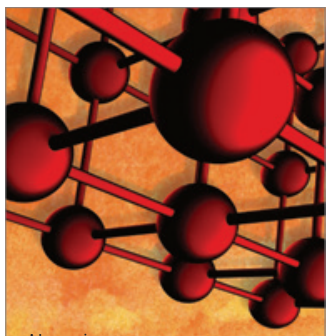

Materials Science and Engineering
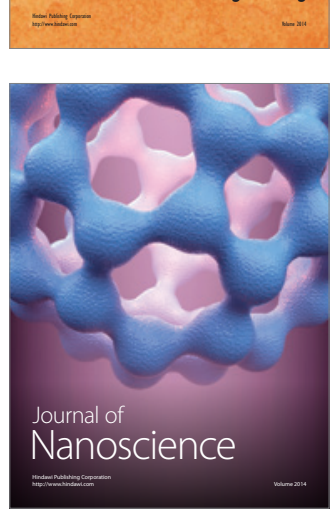
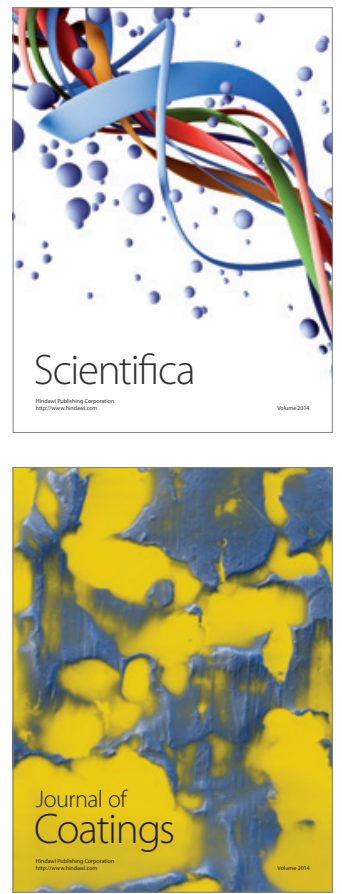
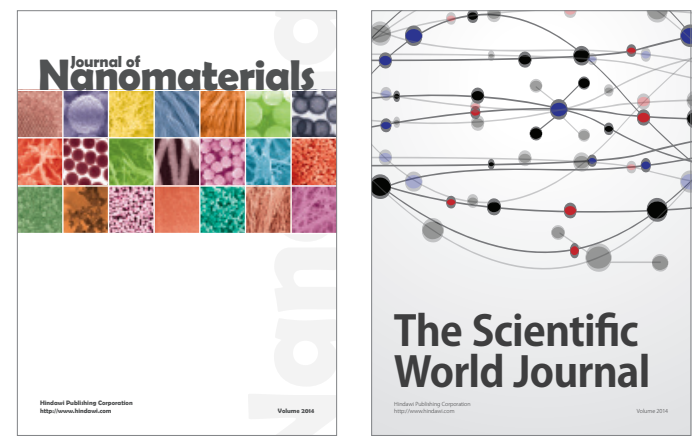

The Scientific World Journal
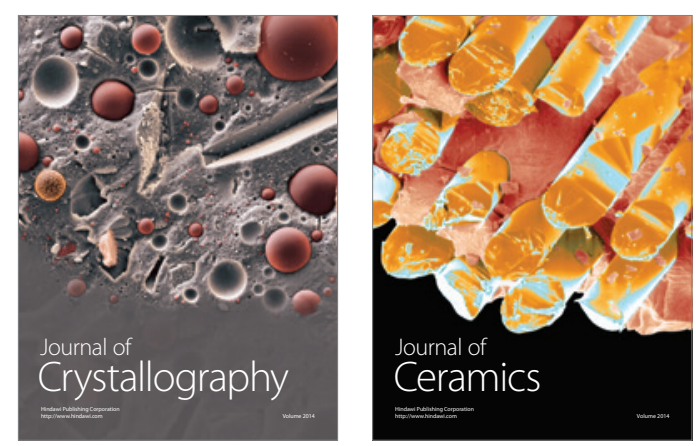
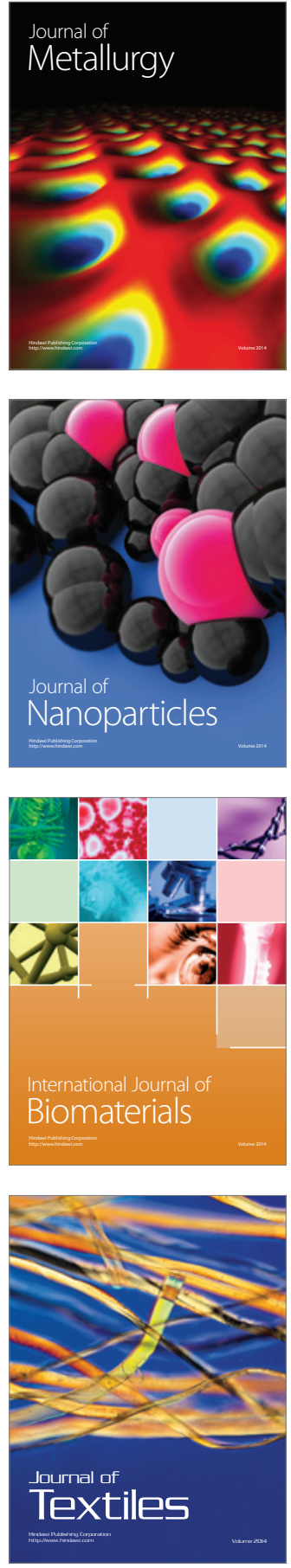